\title{
Barriers to establish e-business for developing tourism industry: A case study of Kish Island
}

\author{
Ardeshir Tajzadeh Namin
}

Faculty of Management and Accounting, Allameh Tabataba'i University, Tehran, Iran

\begin{tabular}{|c|c|}
\hline A R T I C L E I N F O & A B S T R A C T \\
\hline $\begin{array}{l}\text { Article history: } \\
\text { Received July 20, } 2011 \\
\text { Received in Revised form } \\
\text { October, 12, } 2011 \\
\text { Accepted } 15 \text { October } 2011 \\
\text { Available online } \\
25 \text { October } 2011 \\
\text { Keywords: } \\
\text { e-business } \\
\text { Analytical hierarchy process } \\
\text { Tourism industry }\end{array}$ & $\begin{array}{l}\text { This is an empirical study for ranking different barriers on developing e-business in one of the } \\
\text { free zones called Kish Island. This Island is located in south part of Iran and it is one of the } \\
\text { most beautiful free zones of this country with tremendous opportunities for tourism industry. } \\
\text { The proposed study gathers important factors in five different groups of economical, social and } \\
\text { cultural, political, technology and software packages. In each group, decision makers determine } \\
\text { various influencing factors and after three rounds of brainstorming, analytical hierarchy process } \\
\text { is used to rank these factors. Based on the results, the lack of a good infrastructure (0.206), the } \\
\text { lack of good culture among ordinary people to use e-businesses (0.205), the lack of good } \\
\text { knowledge on internet services among ordinary people (0.204) are some of the most important } \\
\text { factors preventing e-business in this region. }\end{array}$ \\
\hline
\end{tabular}

Kish Island

\section{Introduction}

During the past two decades, there have been tremendous changes on the way people do their businesses. Many people prefer to pay their bills using telephone bank, online banking or purchase their products or services using debit or credit cards. People prefer not to carry cash because of the risk involved especially when they travel to other cities or countries. Tourism industry is one of the most important sectors especially for countries with precious history and lots of monuments. Countries with lots of ancient histories have tremendous opportunities to boost their economies though developing tourism industry. However, there are many barriers such as social, economical, technological and political in developing tourism industry. There are many studies to detect barriers for developing e-business (Leonidou, 1999; Walczuch et al., 2000). Phillips and Wright (2009) discussed how e-business could increase the flexibility of organizations through reducing their size and human resources.

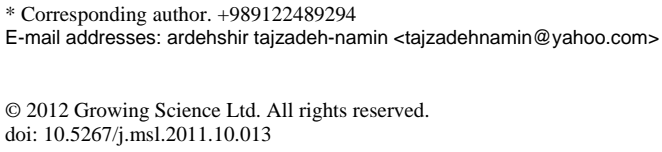


Lee and Kozar (2006) investigated the effect of website quality on e-business success using an analytic hierarchy process (AHP) approach. The study disclosed various relative importance of each website quality factor and priority of alternative websites across e-business domains and between stakeholders and reported that the website with the highest quality produced the highest business performance. Zheng et al. (2004) discussed the impact of cost/benefit of implementing e-businesses.

Kshetri (2007) discussed barriers to e-commerce and competitive business models in developing countries. Kshetri incorporated three groups of feedback systems-economic, sociopolitical and cognitive to provide a simple model of e-commerce barriers in the developing world. The framework examined characteristics of e-business models, which could be successfully employed in developing countries. Howard et al. (2006) presented a comprehensive method on automotive business to business, e-hubs, by exploring motivations and barriers to collaboration and interaction. During the past few years, many organizations are using e-hubs to reduce their costs. They investigated collaboration and interaction by examining four cases of e-hub adoption by vehicle manufacturers and suppliers. They developed a conceptual framework to evaluate the real benefits of electronic applications by revealing firm and industry level motivations and barriers. The framework explained the dissonance between expected and realized benefits, and extended the literature on the barriers. They concluded with recommendations for how best to adopt e-hubs in terms of supply topology, buyer-supplier relationships, leadership, and the threat of from e-hubs.

Soto-Acosta et al. (2008) analyzed e-business value creation from a resource-based perspective. They developed a framework, grounded in the resource-based theory, for assessing e-business value creation. The proposed model considered three relationships including internet resources and ebusiness value, Internet resources and e-business capabilities, and e-business capabilities and ebusiness value. They used a sample of 1010 Spanish firms to test their hypotheses and reported that internet resources per se were not positively correlated with e-business value. In addition, although internet resources were not positively correlated to e-business value, they play an essential role in creating e-business capabilities.

The proposed study of this paper performs a comprehensive study to collect all-important factors influencing implementation of e-business for developing tourism industry in Kish Island. The orientation of this paper first proposes the structure of the research in section 2. Section 3 presents the results of our survey and the paper finishes by concluding remarks in section 4 .

\section{The proposed study}

During the last few years, internet has changed world, significantly. The recent changes in Middle East political changes especially in Egypt were partly initiated through different discussions held on social websites. The increase use of internet facilities has many advantages since many organizations prefer to sell their products or services via internet facilities. There are different barriers in developing e-business units in many countries and the present study performed an empirical study on one of free zone areas of Iran called Kish Island. The study gathered different factors through three rounds of brainstorming and Delphi discussions.

Table 1 summarizes some of the most important factors preventing implementation of e-business in this free zone. As the results of our survey in this table show, third item, which is associated with the inadequate support for private organizations to invest in e-business sector and strategic planning from the governmental agencies, has become the most important barrier followed by the relative high infrastructure cost of internet for ordinary people. In addition, it seems that internet usage has become relatively expensive for the people who live in Kish Island and e-business success depends on providing cheaper services for these people. The other important issue is the rapid change on ebusiness infrastructure, which requires spending significant amount of investment for upgrading 
technology. Since Iran is experiencing various economic sanctions, it is virtually impossible to purchase goods and services via international credit cards making it more difficult to sell goods and services in this area.

\section{Table 1}

Important economical factors preventing implementation of e-business in Kish Island free zone

\begin{tabular}{llcc}
\hline Item & Title & Frequency & Percent \\
\hline 1 & High levels of the cost of building infrastructure, satellite, etc. & 28 & 93 \\
2 & Inability of private sector to invest in this sector & 20 & 66 \\
3 & Inadequate support for private organizations to invest in e-business sector & 29 & 96 \\
4 & Unknown rate of return of investment in this sector & 19 & 63 \\
5 & The high cost of using internet for ordinary people & 27 & 90 \\
6 & The high cost of hiring IT experts as well as doing e-business & 17 & 56 \\
7 & The lack of a difference between the regular and e-business prices & 15 & 50 \\
8 & Economic sanction & 26 & 86 \\
9 & The high cost of upgrading e-business infrastructures & 26 & 86 \\
10 & Rapid change in laws and regulations & 21 & 70 \\
\hline
\end{tabular}

The other important barriers are social and cultural factors influencing implementation of e-business for the case study of the proposed study and we have collected seven factors summarized in Table 2.

\section{Table 2}

Important social and cultural factors preventing implementation of e-business in Kish Island free zone

\begin{tabular}{llcc}
\hline Item & Title & Frequency & Percent \\
\hline 1 & The lack of a good culture for using e-business among people & 30 & 100 \\
2 & The lack of people's familiarity with the advantages of using e-business & 20 & 66 \\
3 & The lack of a mutual trust among people for disclosing their private information & 29 & 96 \\
4 & The unknown nature of e-business & 22 & 73 \\
5 & $\begin{array}{l}\text { Inadequate e-business culture (e.g., training, e-enhancement, etc.) by private and } \\
\text { public sectors }\end{array}$ & 25 & 83 \\
6 & Resistance of private and public sectors against rapid changes & 23 & 76 \\
7 & The conflict between religious and cultural values with e-business & 13 & 43 \\
\hline
\end{tabular}

As we can observe from the results of Table 2, the lack of a good culture for using e-business among people plays an important role since all decision makers agreed on this item. The other important factor was that people do not trust in e-business system. Our decision makers did not mostly agree on other items. Regulation and political issues are other important factors preventing people to use ebusiness in this region. Table 3 summarizes details of our survey.

\section{Table 3}

Important political factors preventing implementation of e-business in Kish Island free zone

\begin{tabular}{llcc}
\hline Item & Title & Frequency & Percent \\
\hline 1 & The lack of a good secure internet system and the laws to support them & 29 & 96 \\
2 & The sanction imposed on the country & 24 & 80 \\
3 & Not adequate policy and strategic planning & 30 & 100 \\
4 & The lack of a comprehensive regulation & 22 & 73 \\
5 & Filtering website(s) based on political considerations & 19 & 63 \\
6 & The lack of a good support and intellectual property laws & 23 & 76 \\
7 & The lack of a good standard system and different decision makers & 24 & 80 \\
8 & The lack of a proper use of e-business due to weak knowledge & 27 & 90 \\
\hline
\end{tabular}

Based on the results of Table 3, all our decision makers believe government does not provide good support to develop e-business system in this region. The security is the second important factor discouraging people to use e-business, the lack of a sufficient knowledge is the third important factor and the economic sanctions as well as the lack of a good standard are other important factors 
preventing people to use e-business systems. The other important groups of demotivating factors are information technology infrastructures, which are summarized in Table 4.

Table 4

Important technology factors preventing implementation of e-business in Kish Island free zone

\begin{tabular}{llcc}
\hline Item & Title & Frequency & Percent \\
\hline 1 & All people do not have equal access to internet facilities & 28 & 93 \\
2 & The lack of a good infrastructure & 30 & 100 \\
3 & The lack of high speed internet facilities & 29 & 96 \\
4 & The lack of a good marketing system & 22 & 73 \\
5 & Weakness in upgrading security systems & 27 & 90 \\
6 & Weakness in local intranet and internet systems & 26 & 86 \\
7 & Few numbers of service provider & 20 & 66 \\
8 & The lack of a good supervision of proper use of e-business system & 23 & 76 \\
\hline
\end{tabular}

According to the survey, all decision makers blamed weak infrastructure as the most important barriers for implementing e-business. In addition, the lack of a good infrastructure, low internet services and weakness in upgrading security systems are other important factors.

\section{Table 5}

Important software factors preventing implementation of e-business in Kish Island free zone

\begin{tabular}{llcc}
\hline Item & Title & Frequency & Percent \\
\hline 1 & The lack of web specialist and marketing experts & 22 & 73 \\
2 & The lack of a good insight on the advantages of e-business & 25 & 83 \\
3 & The lack of a good knowledge among people & 30 & 100 \\
4 & The weakness on computer security & 30 & 100 \\
5 & The weal level of educational knowledge & 23 & 76 \\
6 & Weakness in accessing good programmers & 22 & 73 \\
7 & Weakness in service provider capabilities & 19 & 63 \\
8 & The lack of a good knowledge and proper use of software packages & 17 & 90 \\
\hline
\end{tabular}

According to the results of Table 5, the lacks of good knowledge among people as well as the weakness on computer security are to blame as the most important barriers of e-business.

\section{The results}

In this section, we present details of implementation of analytical hierarchy process (AHP) for ranking five groups of economical, social and cultural, political, technological and software issues (Saaty, 1996). Fig. 1 demonstrates the ranking for each component.

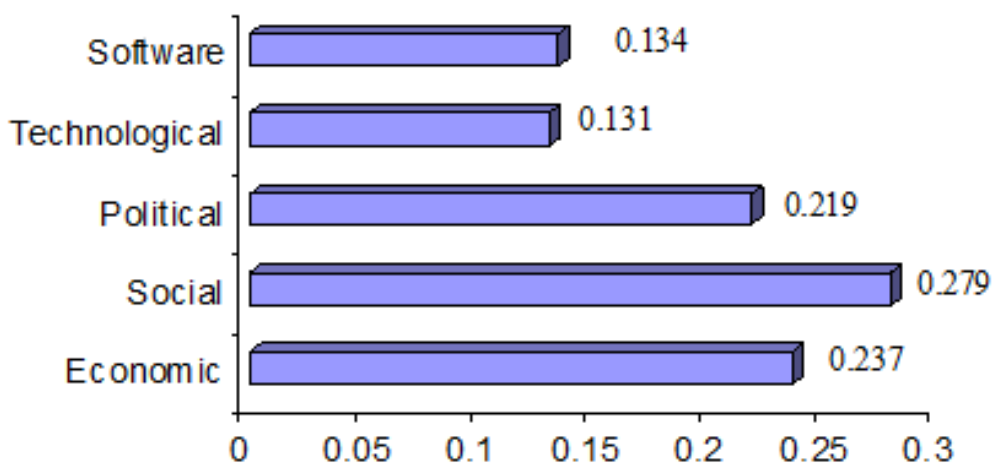

Fig. 1. Ranking five groups based on AHP, Consistency ratio <.1 
As Fig.1 shows, social factors are the most important item followed by economical and political issues are other important factors. The pairwise comparison of all mentioned components is made in section 2 for each group.

\subsection{Economical factors}

The economical factors play important role on developing e-business and the pairwise comparisons are made among these factors summarized in Fig. 2.

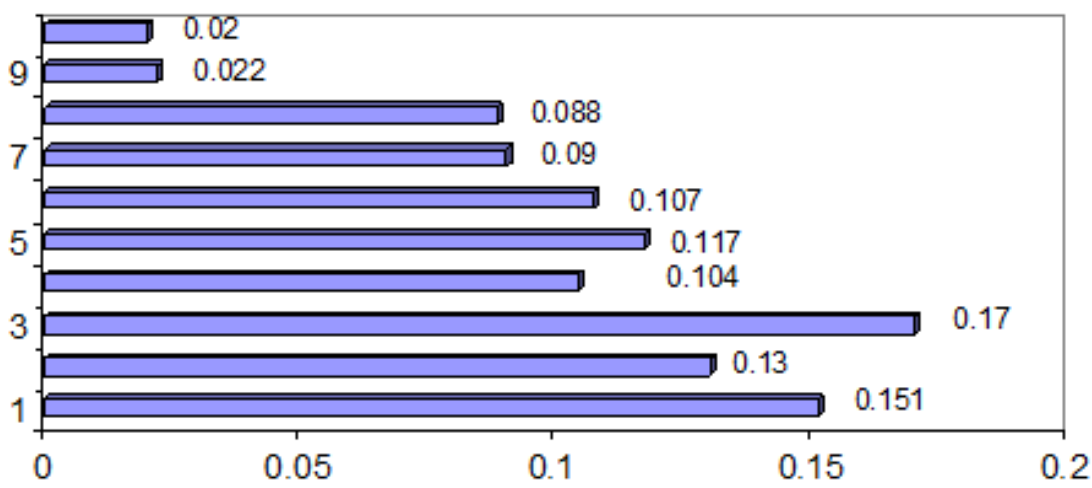

Fig. 2. Ranking of economical factors, inconsistency ration $<.01$

\subsection{Social and cultural factors}

Social and cultural factors are other important factors playing vital role in developing e-business and the results of pairwise comparison and AHP implementation are shown in Fig 3.

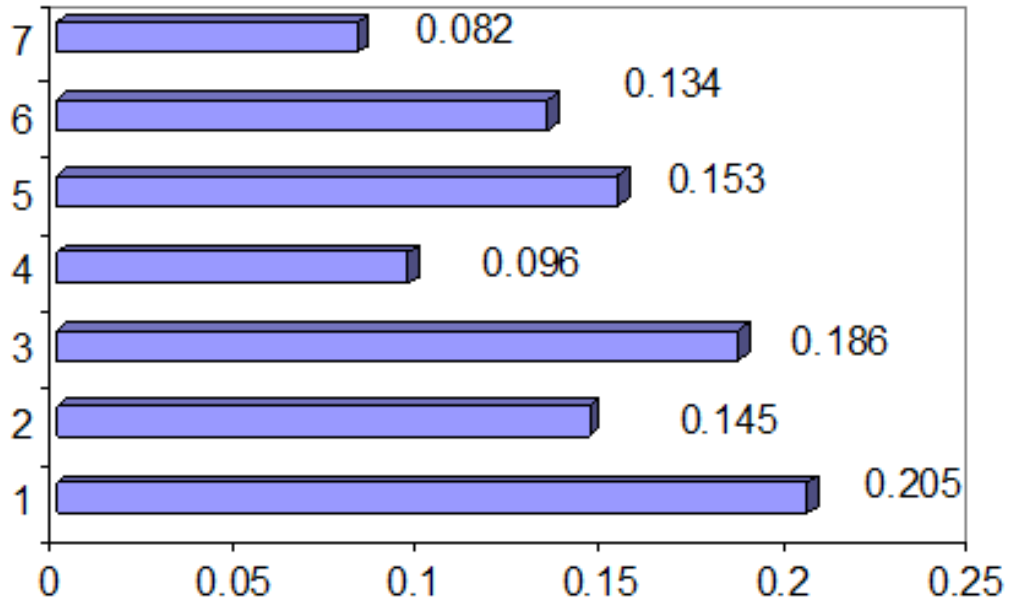

Fig. 3. Ranking of social and cultural factors, inconsistency ration $<.01$

As the results show, culture plays an important role on bringing success on technology. The other pairwise comparisons have also been performed and the whole procedure of AHP is applied, which yields the relative importance of all factors. Based on the results, the lack of a good infrastructure (0.206), the lack of good culture among ordinary people to use e-businesses (0.205), the lack of good knowledge on internet services among ordinary people (0.204) are the first most important factors on developing e-business. The other important factors are the lack of mutual trust among people (0.186), the inadequate support for private organizations to invest in e-business sector (0.170), the lack of good educational background (0.153), the lack of equal access among all people (0.152), the high cost of upgrading infrastructure (0.151), weak regulation policy (0.150), weak internet services (0.149), 
shortage of senior software engineers and the lack of familiarity with e-business advantages are considered as the secondary issues.

\section{Conclusion}

This paper presented an empirical study for ranking different barriers on developing e-business in one of the free zones called Kish Island, which is one of the most beautiful free zones of this country. The proposed study gathered important factors in five different groups of economical, social and cultural, political, technology and software packages. In each group, decision makers determined various influencing factors and after three rounds of brainstorming, analytical hierarchy process has been used to rank these factors. Based on the results, the lack of a good infrastructure (0.206), the lack of good culture among ordinary people to use e-businesses (0.205), the lack of good knowledge on internet services among ordinary people (0.204) are the first most important factors on developing ebusiness. The other important issues were the lack of mutual trust among people $(0.186)$, the inadequate policy and strategic planning from the government (0.170), the lack of good educational background (0.153), the lack of equal access among all people (0.152), the high cost of upgrading infrastructure (0.151), weak regulation policy (0.150), weak internet services (0.149), shortage of senior software engineers and the lack of familiarity with e-business advantages are considered as the secondary issues.

\section{Acknowledgment}

The authors would like to thank the anonymous referees for constructive comments on earlier version of this work.

\section{References}

Howard, M., Vidgen, R., \& Powell, P. (2006). Automotive e-hubs: Exploring motivations and barriers to collaboration and interaction. The Journal of Strategic Information Systems, 15(1), 5175.

Kshetri, N. (2007). Barriers to e-commerce and competitive business models in developing countries: A case study. Electronic Commerce Research and Applications, 6(4), 443-452.

Lee, Y., \& Kozar, K.A. (2006). Investigating the effect of website quality on e-business success: An analytic hierarchy process (AHP) approach. Decision Support Systems, 42(3), 1383-1401.

Leonidou, L.C. (1999). Barriers to international purchasing: the relevance of firm characteristics. International Business Review, 8(4), 487-512.

Phillips, P.A., \& Wright, C. (2009). E-business's impact on organizational flexibility. Journal of Business Research, 62(11), 1071-1080.

Walczuch, R., Van Braven, G., \& Lundgren, H. (2000). Internet adoption barriers for small firms in The Netherlands. European Management Journal, 18(5), 561-572.

Saaty, T.I. (1996). The Analytical Network Procedures, Planning Resource, Allocation. USA: RWS publication.

Soto-Acosta, P., \& Meroño-Cerdan, A. L. (2008). Analyzing e-business value creation from a resource-based perspective. International Journal of Information Management, 28(1), 49-60.

Zheng, J., Caldwell, N., Harland, C., Powell, P., Woerndl, M., Xu, S. (2004). Small firms and ebusiness: cautiousness, contingency and cost-benefit. Journal of Purchasing and Supply Management, 10(1), 27-39. 